\title{
PENGARUH BEBERAPA DOSIS ETILEN PADA PEMBUNGAAN TANAMAN NANAS (Ananas comosus L.) VARIETAS QUEEN
}

\author{
Palupi Puspitorini dan \\ Tri Kurniastuti
}

Dosen Fakultas Pertanian, Universitas Islam Balitar Blitar

\begin{abstract}
ABSTRAK
The study aimed to determine the best dose of ethylene solution in flowering of pineapple plants. The study used a Randomized Block Design (RBD) trial pattern with repeated 4 times. The dose treatment of ethylene concentration, namely: $A I=0.25 \mathrm{ml} . \mathrm{L} \mathrm{A2}, A 2=0.5 \mathrm{ml} . \mathrm{L} \mathrm{A3}$, $A 3=0.75 \mathrm{ml} . \mathrm{L}^{1}, A 4=1 \mathrm{ml} . \mathrm{L}^{1}, A 5=1.25 \mathrm{ml} . \mathrm{L}^{1}, A 6=1.5 \mathrm{ml} . \mathrm{L}^{1}, A 7=1.75 \mathrm{ml} . \mathrm{L}^{1}$ And 3 treatments for each treatment were taken as samples. The results showed that the treatment of administration of ethylene $1.5 \mathrm{ml} . \mathrm{L}^{1}$, is the best treatment for stimulating flowers on pineapple plants.
\end{abstract}

Keywords: flowers, ethylene, pineapple

\section{PENDAHULUAN}

Di Indonesia nanas merupakan komoditas ekspor, dimana setap tahun permintaan nanas terus meningkat ${ }^{(1)}$. Budidaya tanaman nanas menjadi sangat penting, karena kebutuhan buah nanas di dunia semakin meningkat dari tahun ke tahun ${ }^{(2)}$. Keberhasilan budidaya tanaman nanas hingga panen atau sampai menghasilkan buah, selain dari proses budidaya, sangat ditentukan keberhasilan bunga yang nantinya akan menjadi buah. Menurut Bartholomew et al ${ }^{(3)}$ untuk menginduksi bunga pada tanaman nanas biasanya diinisiasi dengan zat pengatur tumbuh. Pemacu penggunaan etilen salah satunya. Secara alamiah tanaman nanas akan berbuah dengan sendirinya bila sudah dewasa, tetapi todak serempaknya bunga akan menimbulkan masalah pada rendahnya produksi. Permasalahan yang ada adalah keberhasilan prosentasi bunga masih di bawah $98 \%$ dari total populasi ${ }^{(4)}$ walaupun sudah dilakukan perangsangan bunga (forcing).

Forcing adalah teknik perangsangan pembungaan untuk menyeragamkan perubahan pertumbuhan dari vegetative ke generative yang terjadi pada jaringan meristematik tanaman 
Jurnal Viabel Pertanian Vol. 12 No.2 November 2018

p-ISSN: 1978-5259 e-ISSN: 2527-3345

Copyright@UNISBA Blitar, http://viabel.unisbablitar.ejournal.web.id

Palupi Puspitorini, Tri Kurniastuti. 2018. Pengaruh Beberapa Dosis Etilen Pada Pembungaan

Tanaman Nanas (Ananas comosus L. Varietas Queen. Journal Viabel Pertanian. (2018), 12 (2) 11 19

nanas. Bahan kimia yang digunakan untuk forcing mengandung etilen dan asetilen yang secara alami diproduksi tanaman nanas sebagai hormone dalam tumbuhan nanas. Keberhasilan forcing dapat ditentukan melalui pengamatan persen bunga 45 hari setelah forcing $^{(5)}$.

Ethephon cepat memberikan respon dalam merangsang pembungaan pada tanaman nenas. Keberhasilan dari penggunaan Ethephon pada pembungaan dipengaruhi oleh konsentrasi, cara penggunaan, varietas dan macam bibit yang ditanam. Bondad (2006) terhadap tanaman nenas yang berumur 14 bulan, yang disiram dengan $50 \mathrm{ml}$ Ethephon dengan konsentrasi 1000 ppm pada batang pokoknya (jantungnya), akan menyebabkan $85 \%$ dari tanaman tersebut berbunga 80 hari setelah dilakukan penyiraman ${ }^{(3)}$. Tanaman yang tidak disiram masih dalam keadaan vegetatif. Tanaman nenas yang disemprot dengan larutan Ethephon konsentrasi 1, 2 dan 4 lb/hektar dapat menyebabkan tanaman 100\% berbunga, sementara tanaman kontrol masih tetap dalam keadaan vegetatif.

\section{BAHAN DAN METODE}

Bahan yang digunakan dalam penelitian ini adalah 675 tanaman nanas umur 10 bulan, hormone etilen, pupuk urea, pupuk NPK dan air aqua.

Alat yang digunakan dalam penelitian ini adalah timbangan digital, pipet, pengukur, pengaduk, botol tempat larutan etilen sarung tangan, sepatu boat, ember, alat tulis, penggaris besi, jangka sorong.

Penelitian menggunakan Rancangan Acak Kelompok (RAK) pola percobaan dengan diulang 4 kali. Perlakuan dosis konsentrasi etilen, yaitu : AI =0.25ml.L-1 , A2 =0,5ml.L- ${ }^{1}$,A3

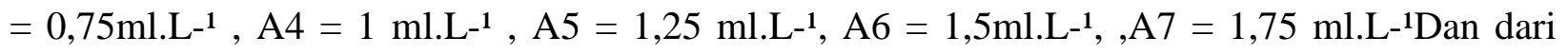
masing-masing perlakuan diambil 3 tanaman sebagai sampel.

Aplikasi pemberian larutan etilen dilakukan pada umur 10 bulan setelah tanam, rata-rata tinggi tanaman $90 \mathrm{~cm}$ dengan bobot tanaman rata-rata $1,5 \mathrm{~kg}$.

Variable peubah pengamatan meliputi : 


\section{Diameter Bunga}

Pengukuran diameter bunga dilakukan sejak kemunculan bunga pada umur pengamatan 40 hsf, 50 hsf, 60 hsf dengan satuan $\mathrm{cm}$.

\section{Keberhasilan Forcing (KF)}

Keberhasilan Forcing (KF) parameter yang digunakan berpa total prosentase muncul bunga awal penelitian sampai akhir penelitian. Parameter diukur berdasarkan hitungan 60 hsf, dengan rumus :

$$
\mathrm{KF}=\frac{\text { TOTAL BUNGA } 60 \mathrm{HSF} \times 100 \%}{\text { JUMLAH TANAMAN }}
$$

Forcing dapat dinyatakan berhasil jika pada suatu lokasi, jumlah tanaman yang berbunga lebih dari $98 \%$ dan dikatakan gagal jika kurang dari $98 \%$.

\section{Kecepatan Muncul Bunga}

Kecepatan Muncul Bunga (KMB) diukur berdasarkan jumlah tanaman bunga selama kurun waktu penelitian, dengan rumus :$$
\mathrm{KMB}=\underline{\mathrm{N} 1 \mathrm{~T} 1+\mathrm{N} 2 \mathrm{~T} 2+\ldots \ldots .+\mathrm{NxTx}}
$$$$
\text { Jumlah Tanaman Dibungakan }
$$$$
\text { KMB : Kecepatan Muncul Bunga }
$$$$
\mathrm{N} \quad \text { : Jumlah tanaman yang berbunga pada satuan waktu tertentu }
$$$$
\mathrm{T} \quad \text { : Jumlah waktu antara awal pengujian sampai dengan akhir pengamatan }
$$ 


\section{HASIL DAN PEMBAHASAN}

\section{Diameter Bunga}

Berdasarkan hasil analisis sidik ragam (ANOVA) pada taraf 5\% menunjukkan bahwa terdapat perbedaan yang nyata nyata perlakuan dosis Etilen (A) terhadap diameter bunga tanaman nanas umur pengamatan $40 \mathrm{HSF}, 50 \mathrm{HSF}$ dan $60 \mathrm{HSF}$. Untuk mengetahui perlakuan terbaik dilakukan Uji Duncan's taraf 5\% pada umur pengamatan $40 \mathrm{HSF}, 50 \mathrm{HSF}$ dan $60 \mathrm{HSF}$ dapat dilihat pada table 1 .

Tabel 1. Pengaruh Dosis Etilen (A) Terhadap Diameter Bunga Tanaman Nanas pada 40HSF,50HSF,60HSF

\begin{tabular}{cccc}
\hline & \multicolumn{3}{c}{ Rerata Diameter Bunga } \\
Perlakuan & \multicolumn{3}{c}{ Tanaman Nanas } \\
& $40 \mathrm{HSF}$ & $50 \mathrm{HSF}$ & $60 \mathrm{HSF}$ \\
\hline A1 & $1,47 \mathrm{a}$ & $2,50 \mathrm{a}$ & $2,75 \mathrm{a}$ \\
A2 & $1,70 \mathrm{ab}$ & $3,77 \mathrm{bc}$ & $4,24 \mathrm{~b}$ \\
A3 & $2.00 \mathrm{~b}$ & $3,76 \mathrm{bc}$ & $4,36 \mathrm{~b}$ \\
A4 & $3.09 \mathrm{c}$ & $3.81 \mathrm{c}$ & $4,79 \mathrm{~d}$ \\
A5 & $3,30 \mathrm{~d}$ & $3.44 \mathrm{~b}$ & $4,69 \mathrm{~cd}$ \\
A6 & $3.12 \mathrm{~d}$ & $4.70 \mathrm{~d}$ & $4,93 \mathrm{~d}$ \\
A7 & $2,66 \mathrm{c}$ & $3.52 \mathrm{bc}$ & $3,80 \mathrm{a}$
\end{tabular}

Keterangan : Angka-angka yang di ikuti dengan huruf yang sama pada baris dan kolam yang sama tidak berbeda nyata pada uji Duncan'staraf 5\%.

Dar tabel 1 di atas ditunjukkan bahwa pemberian etilen dengan dosis yang dinaikkan dari 0.25 ml.L-1 hingga 1,50 ml.L-1 telah mampu menaikkan diameter bunga nanas. Pada umur 40, 50 dan 60 HSF ditunjukkan bahwa diameter tertinggi diperoleh pada dosis pemberian etilen 1,50 
ml.L-1 (A6) dengan diameter terbesar yatu 4,93 cm. Hal ini diduga bahwa unsure etilen diperlukan tanaman dalam hal pembungaan, masa transisi dari vegetative ke pembentukan bakal buah pada titik tumbuh tanaman dipercepat dengan pemberian larutan etilen yang merupakan zat pengatur tumbuh endogen atau eksogen yang dapat menimbulkan berbagai respon fisiologis dan morfologis tanaman antara lain mendorong pemecahan dormansi bakal bunga pada titik tumbuh tanaman nanas sehingga mencapai masa matang fisiologis lebih cepat. Pemberian dosis tertinggi pada perlakuan pemberian etilen 1,75 ml.L-1 (A7) menunjukkan diameter lebih rendah dan tidak berbeda nyata dengan perlakuan pemberian etilen dosis 0,25 ml.L-1 (A1). Hal tersebut dibuktikan dengan pernyataan Rahmawati (2010) ${ }^{(6)}$ semakin tinggi konsentrasi etilen maka diameter bunga tanaman nanas akan semakin kecil. Hal ini disebabkan karena ethilen yang diaplikasikan terlalu tinggi akan menghambat kerja auksin yang berguna untuk stimulasi pertumbuhan sel.

\section{Keberhasilan Forcing}

Keberhasilan Forcing(KF) pada pemberian perilaku Etilen (A) dan Urea (B) pada keseragaman pembungaan tanaman nanas menggunakan parameter berupa rata-rata total prosentase muncul bunga pada tanaman nanas dimulai dari awal muncul bunga sampai pada akhir penelitian, yaitu $40 \mathrm{HSF}, 50 \mathrm{HSF}$ dan $60 \mathrm{HSF}$. Untuk mengetahui rata-rata total prosentase muncul bunga tanaman nanas yang terlah diberi perlakuan Etilen dapat dilihat pada table 2 dibawah ini :

Tabel 2. Rata-rata prosentase muncul bunga pada tanaman nanas setelah diberi perlakuan Etilen (A)

\begin{tabular}{cccc}
\hline \multirow{2}{*}{ Perlakuan } & \multicolumn{3}{c}{ Rerata Muncul Bunga (\%) } \\
& 40HSF & 50HSF & $60 \mathrm{HSF}$ \\
\hline A1 & 65.5 & 80 & 90 \\
A2 & 100 & 100 & 100 \\
A3 & 100 & 100 & 100
\end{tabular}


Pada umur pengamatan $50 \mathrm{HSF}$ dan $60 \mathrm{HSF}$ seluruh tanaman nanas pada semua perlakuan sudah muncul bunga 100\%, kecuali pada perlakuan pemberian etilen 0,25 ml.L-1 dan 1,75 ml.L-1 hal ini diduga kemampuan ethepon dalam memecah dormansi terjadi karena etilen yang dilepas akan meningkatkan permeabilitas membrane sel sehingga mempermudah pergerakan molekul ke sitoplasma, dan pada saat umur pengamatan muali 50 HSF kinerja sintesis etilen sudah berjalan optimal sehingga tujuan pembungaan pada tanaman nanas dapat tercapai dengan maksimal. Hal ini sesuai dengan hasil penelitian Bondad (2006) ${ }^{(8)}$ tanaman nanas yang berumur 9 bulan yang disiram dengan 25ml larutan etilen dengan konsentrasi 1000ppm pada batang pokoknya (jantungnya), akan menyebabkan $85 \%$ dari tanaman tersebut berbunga pada 6 minggu setelah melakukan penyiraman, sementara tanaman yang tidak disiram masih dalam keadaan vegetative. Tanaman nanas secara alamiah sudah mengandung hormone pertumbuhan seperti auksin,giberelin dan sitokini yang biasa diistilahkan dengan nama hormone endogen,tetapi pada budidaya yang kurang intensif menyebabkan proses pertumbuhan vegetative dan generative menjadi lambat sehingga pembungaan menjadi tidak serempak, pemberian dosis baik etilen maupun urea harus tepat sebab jika tanaman kelebihan etilen maka auksin akan meningkat dan dapat menyebabkan gagal forcing. Menurut Kushartoyo (1980) ${ }^{(9)}$ etilen yang terkadung pada unsure ethepon cepat memberikan respon dalam merangsang pembungaan pada tanaman nanas. Keberhasilan dalam penggunaan etilen dipengaruhi oleh konsentrasi,cara penggunaan, varietas dan macam bibit yang ditanam.

\section{Kecepatan Muncul Bunga}

Keberhasilan Muncul Bunga pada pemberian perlakuan Etilen (A) dan Urea (B) pada keseragaman pembungaan tanaman nanas menggunakan parameter berupa rata-rata jumlah 
muncul bunga pada tanaman nanas selama kurun waktu penelitian dimulai dari awal muncul bunga sampai pada akhir penelitian, yaitu 40 HSF,50 HSF dan 60 HSF dibagi dengan jumlah tanaman yang dibungakan. Untuk mengetahui rata-rata jumlah muncul bunga tanaman nanas yang terlah diberi perlakuan Etilen, dapat dilihat pada table dibawah ini :

Tabel 3. Pengaruh Etilen (A) Terhadap Kecepatan Bunga Tanaman Nanas pada 40HSF,50HSF,60HSF.

\begin{tabular}{cccc}
\hline \multirow{4}{*}{ Perlakuan } & \multicolumn{3}{c}{ Kecepatan Muncul Bunga } \\
& (\%etmal-1) \\
& 40HSF & 50HSF & $60 \mathrm{HSF}$ \\
\hline A1 & 0,60 & 0,66 & 0,66 \\
A2 & 0,60 & 0,66 & 0,66 \\
A3 & 0,60 & 0,66 & 0,66 \\
A4 & 0,60 & 0,66 & 0,66 \\
A5 & 0,70 & 0,76 & 0,86 \\
A6 & 0,80 & 0,86 & 0,90 \\
A7 & 0,60 & 0,66 & 0,66 \\
& & & \\
\hline
\end{tabular}

Pada umur pengamatan 40 HSF pemberian larutan etilen belum mencukupi kebutuhan bagi tanaman sehingga memperlambat pertumbuhan fisiologis dan mempengaruhi terhadap kecepatan muncul bunga tanaman nanas. Pada umur pengamatan $50 \mathrm{HSF}$ dan $60 \mathrm{HSF}$ prosentase rata-rata kecepatan muncul bunga menunjukkan peningkatan yang sama pada semua perlakuan kecuali pada peerlakuan pemberian etilen 1,50 ml.L-1 (A6) menunujukkan kecepatan bunga tertinggi, pada umur pengamatan 60 HSF merupakan titik maksimal kecepatan muncul bunga hal ini diduga pada umur pengamatan tersebut pemberian larutan etilen yang semakin tinggi dapat meningkatkan kecepatan muncul bunga pada tanaman nanas karena sifat etilen yang 
Jurnal Viabel Pertanian Vol. 12 No.2 November 2018

p-ISSN: 1978-5259 e-ISSN: 2527-3345

Copyright@UNISBA Blitar, http://viabel.unisbablitar.ejournal.web.id

Palupi Puspitorini, Tri Kurniastuti. 2018. Pengaruh Beberapa Dosis Etilen Pada Pembungaan

Tanaman Nanas (Ananas comosus L. Varietas Queen. Journal Viabel Pertanian. (2018), 12 (2) 11 19

mempercepat pertumbuhan generatif sehingga akan mendorong tanaman nanas untuk lebih cepat masak secara fisiologis, namun pemberian dosis etilen harus tepat karena apabila diaplikasikan melebihi dosis yang ditentukan dapat menghambat kecepatan muncul bunga tanaman nanas itu nanas sangat dipengaruhi oleh keidealan kombinasi dosis etilen dan urea karena sifat etilen pada kecepatan muncul bunga tanaman nanas adalah sebagai hormone pemacu tumbuh bunga. Hal ini sesuai hasil penelitian Randhawa dan kawan-kawan pada tahun 1970 dalam Bondad (1976) bahwa penyiraman tanaman nenas Kew dengan $50 \mathrm{ml}$ Ethephon konsentrasi 125 - $2000 \mathrm{ppm}$ pada ujung batang pokok, akan menghasilkan 97 - 98\% dari tanaman berbunga dalam waktu 50 hari setelah perlakuan. Sedangkan tanaman kontrol hanya mampu berbunga $17 \%$.

\section{KESIMPULAN}

Pemberian etilen berpengaruh nyata terhadap pembungaan tanaman nenas. Pemberian etilen pada dosis 1,5 ml. $\mathrm{L}^{-1}$ dapat meningkatkan diameter bunga dan keseragaman bunga.

\section{DAFTAR PUSTAKA}

Abdurachim, M.S. 2009. Identifikasi Faktor-faktor yang Mempengaruhi Keseragaman Pembungaan Tanaman Nanas. Departemen Agronomi dan Holtikultura Fakultas Pertanian Institut Pertanian Bogor. Bogor.

Bartholomew ,Lukito , Bambang M. 2003. Budidaya Nanas Queen. Tri Pusaka. Solo.

Bondad, D. 2006. Respon of Some Tropical and Subtropical Fruit to Pre and Post Harvest Aplications of Ethepon. Economic Botani $30: 67$ - 80.

BPS, 2011. Horticulture statistic. Swamajalah. Solo.

Kushartoyo . 1980. Bertani Nanas. Budi Luhur. Surabaya.

Rachman, Y. 2012. Pengaruh Pemberian Etilen dan Urea (NH2)2CO Terhadap Pertumbuhan dan Hasil Tanaman Nanas. Jurnal Online Mahasiswa 3 (2) : 13-14. 
Jurnal Viabel Pertanian Vol. 12 No.2 November 2018

p-ISSN: 1978-5259 e-ISSN: 2527-3345

Copyright@UNISBA Blitar, http://viabel.unisbablitar.ejournal.web.id

Palupi Puspitorini, Tri Kurniastuti. 2018. Pengaruh Beberapa Dosis Etilen Pada Pembungaan

Tanaman Nanas (Ananas comosus L. Varietas Queen. Journal Viabel Pertanian. (2018), 12 (2) 11 19

Rahmawati. 2010. Pengaruh Varietas dan Konsentrasi Ethilen terhadap Pertumbuhan dan Hasil Tanaman Nanas (Ananas comosus (L.) Merr). Pertiwi. Jakarta. Hlm 28-33.

Sabari. 2006. Budidaya Nanas Lahan Tropis. Tripamula. Bandung.

Syah, M.A.I. 2015. Pengaruh Pemberian Beberapa Dosis Pupuk NPK Tablet terhadap Pertumbuhan dan Produksi Tanaman Nanas (Ananas comosus (L.) Merr). Fakultas Pertanian Universitas Riau. Jurnal Online Mahasiswa 2 (1) : 1-8.

Syaifuddien, Mohammad A. 2009. Identifikasi Faktor-faktor yang Mmepengaruhi Keseragaman Pembungaan Tanaman Nenas (Ananas comosus L. Merr) Di Pt. Great Giant Pineapple, Terbanggi Besar, Lampung Tengah. Fakultas Pertanian. Institut Pertanian Bogor. 